\title{
molecules
}

ISSN 1420-3049

(C) 2008 by MDPI

www.mdpi.org/molecules

Full Paper

\section{Contribution to the Analysis of the Essential Oil of Helichrysum italicum (Roth) G. Don. - Determination of Ester Bonded Acids and Phenols}

\author{
Josip Mastelić $^{1{ }^{*},}$, Olivera Politeo ${ }^{2}$ and Igor Jerković $^{1}$ \\ ${ }^{1}$ Department of Organic Chemistry, Faculty of Chemistry and Technology, N. Tesle 10/V, 21000 \\ Split, Croatia; Fax: 0038521329 461; E-mail: igor@ktf-split.hr \\ ${ }^{2}$ Department of Biochemistry, Faculty of Chemistry and Technology, N. Tesle 10/V, 21000 Split, \\ Croatia; Fax: 0038521329 461; E-mail: olivera@ktf-split.hr
}

* Author to whom correspondence should be addressed; E-mail: josip.mastelic@ktf-split.hr

Received: 6 March 2008; in revsed form: 3 April 2008 / Accepted: 3 April 2008 / Published: 7 April 2008

Abstract: The essential oil of Helichrysum italicum (Roth) G. Don (everlasting or Immortelle essential oil) was isolated by hydrodistillation and analysed by GC and GCMS. Forty four compounds were identified. The main components were $\alpha$-pinene $(12.8 \%), 2$-methyl-cyclohexyl pentanoate $(11.1 \%)$, neryl acetate $(10.4 \%), 1,7$-di-epi- $\alpha$ cedrene $(6.8 \%)$ and other compounds. The oil was fractionated and ester-containing fraction was hydrolysed with $\mathrm{KOH} / \mathrm{H}_{2} \mathrm{SO}_{4}$. The liberated volatiles were analysed by $\mathrm{GC}$ and GC-MS: three phenols and twenty seven volatile carboxylic acids were identified [70\% low fatty acids $\left(\mathrm{C}_{2}-\mathrm{C}_{5}\right), 15 \% \mathrm{C}_{10}-\mathrm{C}_{12}$ acids and $15 \%$ other acids]. The main acids were acetic acid (24.3\%) propanoic acid (17.2\%), 2-methylpropanoic acid (11.4\%), dodecanoic acid (8.7\%), 2-methylbutanoic acid (8.3\%), (Z)-2-methylbutenoic acid $(5.1 \%)$ and decanoic acid (4.6\%). With respect to the identified bonded carboxylic acids, the minimal number of esters in the oil was twenty seven, but their overall quantity was probably larger due to different possible combinations of alcohols with acids to form esters. On the other hand, only six main esters were identified in the oil before fractionation and hydrolysis. 
Keywords: Helichrysum italicum (Roth) G. Don; essential oil; ester bounded acids; GCFID; GC-MS.

\section{Introduction}

The genus Helichrysum, belonging to the family of Asteraceae, consists of a few hundred species, widespread throughout the world. Their flowers, commonly known as gold-everlasting or eternal flowers, were used in antiquity to make the wreaths to crown idols. Helichrysum italicum (Roth) G. Don (everlasting) is a typical Mediterranean plant. It is widespread along the east coast and on the islands of the Adriatic Sea. It is a dwarf aromatic shrub with yellow flowers, up to $50-70 \mathrm{~cm}$ high, growing on dry cliffs and sandy soil. Everlasting is used in traditional medicine due to its antiinflammatory [1-3], antibacterial [4-7] and antioxidant [8,9] properties. The everlasting flower heads contain essential oil that is very sought out by the perfume industry and aromatherapy. The chemical composition of $H$. italicum essential oil of Greek origin has been investigated [10-12]. The chemical composition of the everlasting essential oils from Greece and Croatia are quite different. Oil from Croatia is similar to the oil of Italian origin [13] and its chemical composition varies in relation to the geographic origin and vegetation cycle $[14,15]$. Seasonal and locality variations of everlasting oil from Croatia were investigated in the past [16]. The main components of this essential oil were $\alpha$ pinene, neryl acetate, $\alpha$-cedrene, nerol, $\alpha$-curcumene, $\gamma$-curcumene and geranyl acetate. Essential oils of many plants mainly contain esters of low fatty acids, often acetate, rarely propanoate, butanoate and others. Our earlier study [5] showed the large complexity of everlasting oil chemical composition, with numerous monoterpene, sesquiterpene and nonterpene compounds (hydrocarbons, alcohols, carbonyls, esters, ethers and phenols). The analysis was unreliable, especially in the area of esters, due to numerous peak overlaps in the chromatograms, leading to insufficient separation and identification. According to our early findings, everlasting oil contains numerous ester bonded acids. The aim of this study was to detail investigate ester bounded volatile acids and phenols of everlasting essential oil and their quantitative ratio. For this purpose, the ester-containing oil fraction was hydrolysed, and the liberated volatile acids were isolated and identified by GC and GC-MS.

\section{Results and Discussion}

\section{Chemical composition of everlasting essential oil}

The yield of the essential oil obtained by hydrodistillation was $0.21 \%(\mathrm{w} / \mathrm{w})$ and forty four compounds were identified (Table 1). The main compounds were: $\alpha$-pinene (12.8\%), 2-methylcyclohexyl pentanoate $(11.1 \%)$, neryl acetate $(10.4 \%)$, 1,7-di-epi- $\alpha$-cedrene $(6.8 \%)$, thymol $(5.4 \%)$, eremophilene (4.3\%), limonene (4.0\%), 2,3,4,7,8,8a-hexahydro-1H-3a,7-methanoazulene (3.1\%), $\alpha$ bergamotene $(2.6 \%)$ and ar-curcurmene $(2.3 \%)$. Everlasting essential oil exhibited a very complex composition, with many overlapping peaks on the GC chromatograms. Seven esters were identified, representing $29.0 \%$ of the total oil. 2-Methylcyclohexyl pentanoate and 2-methylcyclohexyl octanoate 
were tentatively identified. Furthermore, thymol (5.4\%), eleven free alcohols (mono- and sesquiterpene alcohols) and six acids [(E)-2-methyl-2-butenoic, octanoic, decanoic, undecanoic, dodecanoic and tetradecanoic acid] were found, representing $3.7 \%$ of the total oil. The oil was neutralised with $\mathrm{NaHCO}_{3}$ and free acids were removed as water soluble salts (Table 1).

Table 1: Chemical composition of everlasting essential oil before and after neutralization.

\begin{tabular}{|c|c|c|c|c|c|}
\hline & \multirow[b]{2}{*}{ Identified compounds } & \multirow{2}{*}{$\begin{array}{c}\text { Before } \\
\text { neutralisation } \\
(\%)\end{array}$} & \multirow{2}{*}{$\begin{array}{c}\text { After } \\
\text { neutralisation } \\
(\%)\end{array}$} & \multicolumn{2}{|c|}{$\boldsymbol{R I}$} \\
\hline & & & & $\begin{array}{l}H P- \\
20 M\end{array}$ & $\begin{array}{c}H P- \\
101 \\
\end{array}$ \\
\hline 1 & $\alpha$-Pinene & 12.8 & 12.9 & 1033 & 913 \\
\hline 2 & Limonene & 4.0 & 4.1 & 1195 & 1014 \\
\hline 3 & Dodecane & 0.3 & 0.3 & 1200 & 1200 \\
\hline 4 & Terpinolene & $\mathrm{t}$ & $\mathrm{t}$ & 1270 & 1060 \\
\hline 5 & Tridecane & $\mathrm{t}$ & $\mathrm{t}$ & 1300 & 1300 \\
\hline 6 & (E)-2-Methyl-2-butenoic acid & 0.7 & - & 1371 & 1317 \\
\hline 7 & $\alpha$-Ylangene & $\mathrm{t}$ & $\mathrm{t}$ & 1462 & - \\
\hline 8 & $\alpha$-Copaene & 1.2 & 1.3 & 1473 & 1354 \\
\hline 9 & $\begin{array}{l}2,3,4,7,8,8 \mathrm{a}-H e x a h y d r o-1 H-3 a, 7- \\
\text { methanoazulene }\end{array}$ & 3.1 & 3.1 & 1531 & 1378 \\
\hline 10 & Fenchol & 0.5 & 0.5 & - & 1096 \\
\hline 11 & $\alpha$-Bergamotene ${ }^{*}$ & 2.6 & 2.6 & 1548 & - \\
\hline 12 & Caryophyllene & 2.0 & 2.1 & 1574 & 1391 \\
\hline 13 & $\gamma$-Gurjunene & 2.4 & 2.4 & 1605 & - \\
\hline 14 & trans-Pinocarveol & 0.1 & 0.1 & 1613 & - \\
\hline 15 & $\alpha$-Humulene & 0.5 & 0.5 & 1639 & - \\
\hline 16 & $\gamma$-Selinene & 0.6 & 0.6 & - & 1438 \\
\hline 17 & $\alpha$-Terpineol & 2.0 & 2.1 & 1658 & 1174 \\
\hline 18 & $\beta$-Selinene & 2.0 & 2.1 & 1662 & - \\
\hline 19 & 1,7-di-epi- $\alpha$-Cedrene & 6.8 & 7.0 & 1674 & - \\
\hline 20 & Neryl acetate & 10.4 & 10.5 & 1697 & 1343 \\
\hline 21 & Eremophilene & 4.3 & 4.5 & 1703 & - \\
\hline 22 & $\delta$-Cadinene & 0.6 & 0.6 & 1726 & - \\
\hline 23 & ar-Curcumene & 2.3 & 4.1 & 1747 & - \\
\hline 24 & Neryl propionate & 0.7 & 0.7 & 1751 & 1685 \\
\hline 25 & Nerol & 1.1 & 1.2 & 1762 & - \\
\hline 26 & 2-Methylcyclohexyl pentanoate ${ }^{t}$ & 11.1 & 11.2 & 1856 & - \\
\hline 27 & 2-Methylcyclohexyl octanoate ${ }^{t}$ & 3.4 & 3.5 & 1872 & 1468 \\
\hline 28 & Nonadecane & $\mathrm{t}$ & $\mathrm{t}$ & 1900 & 1900 \\
\hline 29 & Geranyl propanoate & 2.8 & 2.9 & 1956 & 1421 \\
\hline 30 & Nerolidol $^{*}$ & 0.3 & 0.3 & 1991 & - \\
\hline 31 & Octanoic acid & 0.2 & - & 2002 & - \\
\hline 32 & Guaiol & 2.0 & 2.1 & / & 1567 \\
\hline 33 & Viridiflorol & 1.5 & 1.6 & 2129 & - \\
\hline 34 & Thymol & 5.4 & 5.5 & 2131 & 1374 \\
\hline 35 & Phenylethyl tiglate & 0.6 & 0.6 & 2153 & - \\
\hline
\end{tabular}


Table 1. Cont.

\begin{tabular}{llcccc}
\hline 36 & Torreyol & 0.5 & 0.5 & 2185 & - \\
37 & 1,2,3,3a,4,5,6,7-Octahydro-5- & 0.7 & 0.7 & $/$ & 1632 \\
& azulenmetanol & & & & \\
38 & $\alpha$-Eudesmol & 2.2 & 2.3 & $/$ & 1597 \\
39 & $\beta$-Eudesmol & 3.5 & 3.6 & $/$ & 1613 \\
40 & Decanoic acid & 0.6 & - & $/$ & 1457 \\
41 & Undecanoic acid & 0.3 & - & $/$ & 1532 \\
42 & Dodecanoic acid & 1.1 & - & $/$ & 1617 \\
43 & Tetradecanoic acid & 0.8 & - & $/$ & 1780 \\
44 & Dibutyl phtalate & $\mathrm{t}$ & $\mathrm{t}$ & $/$ & 1906 \\
& & $\mathbf{9 8 . 0}$ & $\mathbf{9 8 . 1}$ & & \\
\cline { 2 - 5 } & Total: & $\mathbf{9 8 . 0}$ & & & \\
\hline
\end{tabular}

$\mathrm{RI}=$ retention indices relative to $\mathrm{C}_{8}-\mathrm{C}_{22} n$-alkanes on polar HP-20M and apolar HP-101 column;

$/$ = retention time was outside of homologous series of $\mathrm{C}_{8}-\mathrm{C}_{22} n$-alkanes, and these compounds were identified using other column; * correct isomer not identified; ${ }^{t}$ tentatively identified - = not identified; $\mathrm{t}=$ trace $<0.1 \%$

\section{Ester-bonded acids and phenols of everlasting essential oil}

After neutralisation, the everlasting essential oil was fractionated and the esters-containing fraction was obtained. This fraction was hydrolysed with $\mathrm{KOH} / \mathrm{H}_{2} \mathrm{SO}_{4}$. The liberated free acidic compounds were analysed by GC and GC-MS (Table 2). Thirty compounds were identified including three phenols and twenty seven carboxylic acids. Phenols (thymol, eugenol and 3-isopropylphenol) were present with overall percentage of $1.3 \%$. This table also shows percentages of acids as mole fractions (for better comparison). The mole fractions were calculated from the mass fractions and molecular weight of each acid.

Table 2: Bound acids and phenols of everlasting essential oil.

\begin{tabular}{llcccc}
\hline & & & & \multicolumn{2}{c}{$\boldsymbol{R I}$} \\
\cline { 4 - 6 } & Identified compound & Area & Mole fraction & HP- & HP- \\
& & \% & \% & 20M & 101 \\
\hline 1 & Acetic acid & 10.7 & 24.3 & 1393 & - \\
2 & Propanoic acid & 9.3 & 17.2 & 1485 & 823 \\
3 & 2-Methylpropanoic acid & 7.4 & 11.4 & 1517 & - \\
4 & Butanoic acid & 0.6 & 1.0 & - & 901 \\
5 & 2-Methylbutanoic acid & 6.2 & 8.3 & 1622 & 985 \\
6 & 2-Methylpentanoic acid & 0.2 & 0.1 & 1715 & - \\
7 & (Z)-2-Methyl-2-butenoic acid & 3.7 & 5.1 & 1728 & 1048 \\
8 & 3-Methyl-2-butenoic acid & 0.5 & 0.7 & 1740 & - \\
9 & 4-Methylpentanoic acid & 0.8 & 1.0 & 1752 & 1050 \\
10 & (E)-2-Methyl-2-butenoic acid & 2.0 & 2.7 & 1790 & 1317 \\
11 & Hexanoic acid & 1.9 & 2.3 & 1793 & 1105 \\
12 & 5-Methyl-5-hexenoic acid & 0.2 & 0.2 & - & 1702 \\
\hline
\end{tabular}


Table 2. Cont.

\begin{tabular}{llcccc}
\hline 13 & 2-Methylhexanoic acid & 0.9 & 1.0 & 1810 & 1127 \\
14 & Heptanoic acid & 0.5 & 0.5 & 1899 & - \\
15 & Octanoic acid & 2.6 & 2.5 & 2002 & 1308 \\
16 & Nonanoic acid & 1.8 & 1.5 & 2110 & 1362 \\
17 & Thymol & 0.6 & - & 2113 & 1374 \\
18 & Eugenol & 0.4 & - & - & 1374 \\
19 & 3-Isopropylphenol & 0.3 & - & 2162 & - \\
20 & C $_{10}$ acid $^{*}$ & 0.5 & 0.3 & 2169 & - \\
21 & Decanoic acid & 5.9 & 4.6 & $/$ & 1457 \\
22 & Undecanoic acid & 1.5 & 1.1 & $/$ & 1532 \\
23 & Benzoic acid & 1.3 & 1.4 & $/$ & 1556 \\
24 & C $_{12}$ acid & 1.4 & 1.0 & $/$ & 1595 \\
25 & Dodecanoic acid & 12.9 & 8.7 & $/$ & 1617 \\
26 & Tridecanoic acid & 1.5 & 1.0 & $/$ & 1713 \\
27 & Tetradecanoic acid & 0.9 & 0.5 & $/$ & 1780 \\
28 & Phenylethanoic acid & 0.2 & 0.1 & $/$ & 1478 \\
29 & 2,5-Dimethylphenyl butanoic acid & 0.7 & 0.4 & $/$ & 1689 \\
30 & Hexadecanoic acid & 1.8 & 1.0 & $/$ & 1991 \\
& & & & & \\
\hline
\end{tabular}

$\mathrm{RI}=$ retention indices relative to $\mathrm{C}_{8}-\mathrm{C}_{22} n$-alkanes on polar HP-20 M and apolar HP-101 column;

$/=$ retention time was outside of homologous series of $\mathrm{C}_{8}-\mathrm{C}_{22} n$-alkanes, and these compounds were identified using other column; " correct isomer not identified; - = not identified

According to these results twenty seven acids were ester bonded. However, Table 1 only contains seven identified esters (acetate, propionate, pentanoate, octanoate, tiglate and phthalate). Therefore, many esters, particular those in small quantities, were overlapped mutually and/or with other compounds and could not be identified due to insufficient chromatographic separation and impure mass spectra. On the other hand, the main identified ester bonded acids (after the hydrolysis) were (mole fractions): acetic acid (24.3\%), propanoic acid (17.2\%), 2-methylpropanoic acid (11.4\%), dodecanoic acid (8.7\%), 2-methylbutanoic acid (8.3\%), (Z)-2-methyl-2-butenoic acid (5.1\%) and decanoic acid (4.6\%). Pentanoic acid was not identified among acids in Table 2, and consequently 2methylcyclohexyl pentanoate was tentatively identified in Table 1 . Low fatty acids $\left(\mathrm{C}_{2}-\mathrm{C}_{5}\right)$ comprised $70 \%$ in the ester fraction, while $\mathrm{C}_{10}-\mathrm{C}_{12}$ acids were present in $15 \%$ and $c a .15 \%$ of other acids were found. According to the identified bonded acids and eleven free alcohols found in the oil, the minimal number of esters in the oil were twenty seven, but their overall quantity was probably larger, due to different possible combinations of alcohols with acids to form esters. Consequently, the ester fraction of this essential oil was very complex. Furthermore under hydrodistillation conditions ( $\mathrm{pH}$, high temperature and long hydrodistillation time) artefacts could be produced. Esters of high fatty acids and high alcohols are usually semi-volatile compounds that belong to plant waxes and appear in low concentrations in essential oils. 


\section{Conclusions}

The essential oil of Helichrysum italicum of Croatian origin exhibits a complex chemical composition, particularly with regards to esters. Thirty compounds were identified after ester hydrolysis (three phenols and twenty seven carboxylic acids). The main identified carboxylic acids (expressed in mole fractions) were acetic, propanoic, isobutyric, isovaleric, dodecanoic and decanoic acid, respectively, followed by $\mathrm{C}_{10}-\mathrm{C}_{12}$ acids and other acids. According to the identified bonded acids, the minimal number of esters present in the oil was twenty seven. Their real number is probably higher considering number of alcohols and their possible mutual combinations with acids to form esters. On the other hand, in the same oil, only seven main esters were identified. Therefore, it can be concluded that many esters present in small quantities were overlapped. They could not be identified in the oil before fractionation and hydrolysis due to their insufficient chromatographic separation and doubtful identification.

\section{Experimental}

\section{Chemicals}

All of the chemicals used were of high purity and were purchased from Fluka Chemie, Buch Switzerland.

\section{Plant material}

Helichrysum italicum (Roth) G. Don. (everlasting) was collected in June 2007 near Split (south Croatia), during the flowering season. Fresh plant material (stems $c a .15 \mathrm{~cm}$ with leaves and flower heads) was used for this research. A voucher specimen is deposited at the Department of Organic Chemistry, Faculty of Chemistry and Technology, University of Split.

\section{Hydrodistillation of the essential oil}

Plant material $(150 \mathrm{~g})$ and water $(750 \mathrm{~mL})$ were placed in a Clevenger type apparatus. The essential oil was isolated by hydrodistillation for three hours. Obtained essential oil was separated, dried over anhydrous sodium sulphate and stored under argon in a sealed vial, at $4{ }^{\circ} \mathrm{C}$ until required for analysis and fractionation.

\section{Neutralisation and fractionation of the essential oil}

The essential oil $(0.5 \mathrm{~g})$ obtained by hydrodistillation, was neutralised by aqueous $\mathrm{NaHCO}_{3}$ solution. The oil was dried over anhydrous sodium sulphate and fractionated on a silica gel column (15 $\mathrm{g} ; 30-60 \mu \mathrm{m})$. Two fractions were obtained. Pentane $(100 \mathrm{~mL})$ was used for the elution of apolar compounds (mono and sesquiterpene hydrocarbons), while diethyl ether $(80 \mathrm{~mL})$ was used for the elution of oxygen-containing compounds (terpenoids). Separation was monitored by thin layer 
chromatography using Kieselgel 60 aluminium-backed sheets (Merck) and by GC-MS. Fraction of apolar compounds (hydrocarbon fraction) was rejected, and diethyl ether fraction was concentrated by careful fractional distillation under diminished pressure.

\section{Hydrolysis of esters}

The oxygen-containing fraction (diethyl ether fraction) that contained all the esters was hydrolysed with a solution of $\mathrm{KOH}$ in ethyl alcohol $(10 \mathrm{~mL}$ ethyl alcohol and $1 \mathrm{~g} \mathrm{KOH})$ for 48 hours at room temperature. After hydrolysis, larger part of ethyl alcohol was removed in a rotatory evaporator under diminished pressure $\left(t=30{ }^{\circ} \mathrm{C}\right)$. The obtained residue was dissolved in water $(30 \mathrm{~mL})$ and the mixture was extracted with petroleum ether-diethyl ether $(5 \times 20 \mathrm{~mL}, 1: 1, \mathrm{v} / \mathrm{v})$. Potassium salts of the acids and phenols remained in the water layer. Free acids and phenols were isolated by extraction with diethyl ether $(7 \times 10 \mathrm{~mL})$ after acidification of the water solution with sulphuric acid ( $\mathrm{pH} 1)$. Combined ether extracts were dried and concentrated to $4 \mathrm{~mL}$ by removing the ether. This solution was used for GC and GC-MS analyses of bonded acids and phenols.

\section{Gas chromatography (GC-FID)}

Gas chromatography analysis was performed on a Hewlett-Packard 5890 Series II gas chromatograph equipped with a flame ionisation detector using a HP-20M capillary column (Hewlett Packard, Carbowax 20M, $50 \mathrm{~m}$ x $0.2 \mathrm{~mm}$ i.d., film thickness $0.2 \mu \mathrm{m}$ ). Chromatographic conditions were as follows: helium as carrier gas at $1.0 \mathrm{~mL} / \mathrm{min}$; injector and detector temperatures, $250{ }^{\circ} \mathrm{C}$ and $300{ }^{\circ} \mathrm{C}$. Oven temperature was isothermal at $70{ }^{\circ} \mathrm{C}$ for $4 \mathrm{~min}$, then increased to $180{ }^{\circ} \mathrm{C}$, at a rate of 4 ${ }^{\circ} \mathrm{C} / \mathrm{min}$ and held isothermal for $15 \mathrm{~min}$. Volume injected $1 \mu \mathrm{l}$. Split ratio 1:50.

\section{Gas chromatography-mass spectrometry (GC-MS)}

The essential oil as well as the fraction of bonded acidic compounds (phenols and acids) were also analysed by Hewlett Packard GC-MS (model 5890 series II) with mass selective detector (model 5971A). Two columns of different polarity were used: a HP-101 column (methyl silicone fluid, Hewlett Packard; $25 \mathrm{~m}$ x $0.2 \mathrm{~mm}$ i.d., film thickness $0.2 \mu \mathrm{m}$ ) and a HP-20M column (Carbowax 20M, Hewlett Packard; $50 \mathrm{~m}$ x $0.2 \mathrm{~mm}$ i.d., film thickness $0.2 \mu \mathrm{m}$ ). GC operating conditions were similar as in our previous paper [17]. Oven temperature was programmed as follows: isothermal at $70{ }^{\circ} \mathrm{C}$ for 4 min, then increased to $180{ }^{\circ} \mathrm{C}$, at a rate of $4{ }^{\circ} \mathrm{C} \mathrm{min}{ }^{-1}$ and subsequently held isothermal for 15 min (for HP-20M column); isothermal at $70{ }^{\circ} \mathrm{C}$ for $2 \mathrm{~min}$, then increased to $200{ }^{\circ} \mathrm{C}$, at a rate of $3{ }^{\circ} \mathrm{C} \mathrm{min}{ }^{-1}$ and held isothermal for $15 \mathrm{~min}$ (for HP-101 column). Carrier gas was helium, flow rate: $1 \mathrm{~mL} \mathrm{~min}^{-1}$; injector temperature: $250{ }^{\circ} \mathrm{C}$; volume injected: $1 \mu \mathrm{L}$; split ratio: 1:50. MS conditions: ionisation voltage: $70 \mathrm{eV}$; ion source temperature: $280{ }^{\circ} \mathrm{C}$; mass range: $30-300$ mass units. 


\section{Qualitative and quantitative determination}

The essential oil yield was determined by the gravimetric method. Quantitative results were obtained from duplicate GC-MS analyses. The individual peaks were identified by comparison of their retention indices to those of authentic samples, as well as by comparing their mass spectra with the Wiley library mass spectral database and literature [18]. The percentage composition of compounds (relative quantity) in the essential oil and fraction of acids were computed from the GC-FID peak areas using the normalization method, without correction factors. These results were obtained as mean of data derived from duplicate GC-FID analyses.

\section{Acknowledgements}

This work was supported by MZOS, Croatia, project "Essential Oils and Flavours Biologically Active Compounds and their Modifications". No 011-098 2929-1329, in the framework of the MZOS "Spectroscopy and Modelling of Bioactive Molecules".

\section{References}

1. Apendino, G.; Ottino, M.; Marquez, N.; Bianchi, F., Gianna, A.; Ballero, M., Sterner, O.; Fiebich, B. L.; Munoz, E. Arzanol, an Anti-inflammatory and Anti-HIV-1 Phloroglucinol $\alpha$-Pyrone from Helichrysum italicum ssp. microphyllum. J. Nat. Prod. 2007, 70, 608 -612.

2. Sala, A.; del Carmen Recio, M.; Schinella, G.; Máñez, S.; Giner, R. M.; Cerdá Nicolás, M.; Ríos, J.-L. New acetophenone glucosides isolated from extracts of Helichrysum italicum with antiinflammatory activity. Eur. J. Pharmacol. 2003, 461, 53-61.

3. Sala, A.; del Carmen Recio, M.; Giner, R. M.; Máñez, S.; Tournier, H.; Schinella, G.; Ríos J.-L. Anti-inflammatory and antioxidant properties of Helichrysum italicum. J. Pharm. Pharmacol. 2002, 54, 365-371.

4. Nostro, A.; Cannatelli, M. A.; Musolino, A. D.; Procopio, F.; Alonzo, V. Helichrysum italicum extract interferes with the production of enterotoxins by Staphylococcus aureus, Lett. App. Microiol. 2002, 35, 181-184.

5. Mastelic, J.; Politeo, O.; Jerkovic, I.; Radosevic, N. Composition and Antimicrobial Activity of Helichrysum italicum Essential Oil and Its Terpene and Terpenoid Fractions. Chem. Nat. Compd. 2005, 41, 35-40.

6. Chinou, I. B.; Roussis, V.; Perdetzoglou, D.; Loukis, A. Chemical and biological studies on two Helichrysum species of Greek origin. Planta Med. 1996, 62, 377-379.

7. Rossi, PG.;Berti, L.; Panighi, J.; Luciani, A.; Maury, J.; Muselli, A.; Serra, DD.;Gonny, M.; Bolla, JM. Antibacterial action of essential oils from Corsica , J. Essent. Oil Res. 2007, 19, 176182.

8. Schinella, G. R.; Tournier, H. A.; Máñez, S.; de Buschiazzo, P. M.; del Carmen Recio, M.; Ríos, J. L. Tiliroside and gnaphaliin inhibit human low density lipoprotein oxidation. Fitoterapia 2007, $78,1-6$. 
9. Maffei Facino, R.; Carini, M.; Franzoi, L.; Pirola, O.; Bosisio, E. Phytochemical characterization and radical scavenger activity of flavonoids from Helichrysum italicum G. Don (Compositae). Pharmacol. Res. 1990, 22, 709-720.

10. Roussis, V.; Tspukatou, M.; Petrakis, P. V.; Chinou, I.; Skoula, M.; Harborne, J. B. Volatile constituents of four Helichrysum species growing in Greece. Biochem. Syst. Ecol. 2000, 28, 63167.

11. Chinou, I. B.; Roussis, V.; Perdetzoglou, D.; Tzakou, O.; Loukis, A. Chemical and antibacterial studies on two Helichrysum species of Greek origin. Planta Med. 1997, 63, 181-183.

12. Chinou, I. B.; Roussis, V.; Perdetzoglou, D.; Loukis, A. Chemical and biological studies on two Helichrysum species of Greek origin. Planta Med. 1996, 62, 377-379.

13. Bianchini, A.; Tomi, P.; Bernardini, A. F.; Morelli, L.; Flamini, G.; Cioni, P. L.; Usai, M.; Marchetti, M. A comparative study of volatile constituents of two Helichrysum italicum (Roth) Guss. Don Fil subspecies growing in Corsica (France), Tuscany and Sardinia (Italy). Flavour Fragr. J. 2003, 18, 487-491.

14. Bianchini, A.; Tomi, P.; Costa, J.; Bernardini, A. F. Composition of Helichrysum italicum (Roth) G. Don fil subsp. italicum essential oils from Corsica (France). Flavour Fragr. J. 2001, 16, 30-34.

15. Paolini, J.; Desjobert, J.-M.; Costa, J.; Bernardini, A.-F.; Castellini, C. B.; Cioni, P.-L.; Flamini, G.; Morelli, I. Composition of essential oils of Helichrysum italicum (Roth) G. Don fil subsp. italicum from Tuscan archipelago islands Flavour Fragr. J. 2006, 21, 805-808.

16. Blažević, N.; Petričić, J.; Stanić, G.; Maleš, Ž. Variation in yields and composition of immortelle (Helichrysum italicum, Roth Guss.) essential oil from different locations and vegetation periods along Adriatic coast. Acta Pharm. 1995, 45, 517-522.

17. Jerković, I.; Mastelić J. Volatile compounds from leaf-buds of Populus nigra L. (Salicaceae) Phytochemistry 2003, 63, 109-113.

18. Adams, R. P. Identification of Essential Oil Components by Gas Chromatography/Mass Spectrometry. Allured Publishing Coorporation: Illinois, 1995.

Sample availability: Contact the authors

(C) 2008 by MDPI (http://www.mdpi.org). Reproduction is permitted for noncommercial purposes. 